\title{
Relationship between Occupational Stress and Depression in Hairdressers
}

\author{
Mi-Jeung Ahn ${ }^{1}$, Sun-Ju Park ${ }^{2 *}$ \\ ${ }^{1}$ Department of Nursing, Andong National University, Andong-si, Gyeongsangbuk-do, Korea \\ ${ }^{2}$ Department of Beauty Business, Yongin University, Yongin-si, Gyeonggi-do, Korea
}

\author{
*Corresponding author: Sun-Ju Park, \\ Department of Beauty Business, Yongin \\ University, 134 Yongindaehak-ro, Cheoin- \\ gu, Yongin-si, Gyeonggi-do 17092, Korea \\ Tel.: +82 3180203694 \\ Fax: +82 3180203694 \\ Email: sj7864@hanmail.net
}

Received October 19, 2020

Revised December 02, 2020

Accepted December 08, 2020

Published December 30, 2020

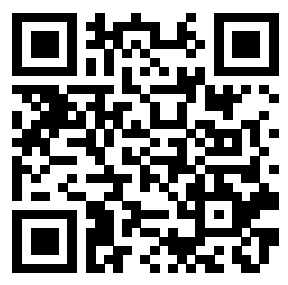

\begin{abstract}
Purpose: This study aimed to investigate job stress in hairdressers, determine its relationship with depression, and identify factors that affect depression. Methods: Levels of job stress and depression according to general characteristics were analyzed using SPSS/WIN 22.0. The correlation between job stress and depression was analyzed using Pearson correction effect. To identify the factors affecting depression, stepwise multiline stress analysis was used. Results: The overall average score for job stress by hairdressers was $41.55 \pm 8.78$, while the average score for depression was $16.79 \pm 9.05$. Variables that appeared to affect depression were inadequate compensation $(t=7.30, p<0.001)$, marital status $(t=-4.53, p<0.001)$, job requirements $(t=2.53, p<0.012)$, age $(t=2.77, p<0.006)$, and workplace culture $(t=246, p<0.015)$. Conclusion: Based on the findings of this study, it is recommended that an intervention program for job stress and depression be developed to improve the mental health of hairdressers.
\end{abstract}

Keywords: Hairdresser, Job stress, Depression, Inadequate compensation, Job requirements

\section{Introduction}

경제성장과 소득수준의 향상으로 미용산업은 생활소비 방식에서 아름다움을 가꾸고 표현하는 문화를 정착시켰다. 2018년 통계청 자 료에 의하면 우리나라 이·미용산업은 2016년 기준 업체 수는 약 13 만 9천개, 근로자는 21 만 2천명이며, 매출액이 연간 6 조 681 억원으 로 매년 $10.8 \%$ 의 성장률로 규모가 증가하는 추세를 보이고 있다. 이 러한 발전과 더불어 미용 서비스 종사자도 매년 증가하고 있다. 우 리나라의 헤어 미용인 수는 2015년 통계청 자료에 의하면 140,162 명으로 5 년 전에 비해 $14 \%$ 이상 증가하였고 이들 헤어 미용인의 86. $3 \%$ 가 여성이고, $99.2 \%$ 가 개인사업체에서 근무하고 있으며, 상 시 근로자가 5 인 미만의 소규모 사업장에서 근무하고 있다

미용산업은 최근 경제성장의 영향으로 서비스 부분이 차지하는 비중이 점차 증가 함에 따라 고객만족에 대한 서비스가 경쟁의 수단 으로 인식되고 있으며(Seo \& Park, 2018), 무형의 서비스를 제공하 는 산업이다(Kim, 2019).
미용산업 중에서 미용 서비스 산업은 인적자원과 정서적인 서비 스, 대인 서비스에 대한 의존도가 높은 산업이며, 소비자들과 대면 하면서 감정적 부조화를 경험하는 경우가 많다. 이러한 감정적 부조 화는 고객을 상대하는 과정에서 감정노동과 언어폭력과 같은 사회 적 스트레스에 노출되어 직무스트레스와 우울이라는 불건강의 형태 로 나타나게 된다.

Centers for Disease Control and Prevention (1999)에서 정의한 직무스트레스는 현대 산업구조의 다양한 요인들에 의해서 발생하 는 복합적 현상이며, 직무요건이 근로자의 능력이나 자원 또는 근로 자의 요구와 일치되지 않을 때 생기는 신체적, 정신적 반응으로 정 의할 수 있다. 미용 서비스업은 고용창출의 효과는 크지만 5 인 미만 의 소규모 사업장이 많으며, 조직의 체계적인 시스템의 부재로 직무 환경 수준이 불량한 경우가 많다. 그리고, 노동의 강도가 크고 복리 후생도 낮은 편이며 근로자의 이동도 빈번하다. 또한 지속적으로 상 완을 드는 부적절한 자세로 장시간 서서 일해야 하는 인간공학적 문 제와 함께 업무의 특성상 일정하게 휴식을 취할 수 없고, 불규칙한 
식사와 운동 부족을 경험하고 있다(Lee \& Lee, 2016). 헤어 미용인 들은 이러한 환경에도 불구하고 소비자의 기대에 부응하며 만족시 키기 위한 소비자 지향적 서비스 제공을 위해 새로운 기술과 지식을 지속적으로 습득해야 하고, 전문성이 요구되어지기 때문에 이에 따 른 심리적, 경제적 부담감은 직무스트레스로 연결된다. 단기간의 직 무스트레스는 위험하지 않지만, 장시간 자주 노출되는 상황이 지속 되고 반복되면 신체는 생물학적 시스템의 균형이 무너져 방어능력 이나 심리적 손상이나 피로가 초래되고 그 결과 우울과 같은 질병 으로 이행 위험이 높아진다. 직무스트레스는 우울증, 불안 등을 일 으키는 위험요인으로서 직무스트레스가 증가할수록 우울, 불안, 스 트레스 증상의 발생이 높으며(Wang et al., 2003), 직무스트레스가 우울의 빈도를 4 배 정도 증가하게 하는 것으로 나타났다(Kessler \& Frank, 1977).

정신·심리적 건강상태를 나타내는 지표인 우울은 스트레스에 대
한 반응으로 정상적인 슬픔 감정에서 심각한 병적 상태에 이르기까 지 넓은 스펙트럼을 가진다. 우울은 업무에 대한 불만족, 의욕상실, 정서적인 갈등 등으로 인해 직무에 대한 생산성 저하에 많은 영향을 주며(Stewant et al., 2003), 생활 전반에 부정적인 결과를 수반한 다.

전체 미용인에 대한 직무스트레스에 대한 선행연구는 활발하게 이루어지고 있지만, 헤어 미용인에 대한 직무스트레스에 대한 선행 연구(Oh \& Song, 2015; Yu et al., 2014; Suh et al., 2011)는 활 발하지 않은 실정이다. 헤어 미용인의 우울에 대한 연구(Lee \& Lee, 2016; Lee, 2015)또한 활발히 이루어지지 않고 있다. 헤어 미용서 비스의 경우 업무의 특성상 직무스트레스가 높은 직업군으로 우울 을 추가로 조사하여 직무스트레스와 우울의 관련성을 파악하는 것 이 필요하다. 헤어 미용인의 직무와 관련된 건강에 관한 국내 선행 연구를 분석한 결과 직무만족도(Park et al., 2013), 감정노동(Lee,

Table 1. General and Job-related characteristics of the subjects

$(\mathbf{N}=\mathbf{1 7 6})$

\begin{tabular}{|c|c|c|}
\hline Characteristics & Categories & $\mathrm{N}(\%)$ or $\mathrm{M} \pm \mathrm{SD}$ \\
\hline \multirow{2}{*}{ Gender } & Male & $36(20.5)$ \\
\hline & Female & $140(79.5)$ \\
\hline \multirow{4}{*}{ Age } & $21-29$ & $47(26.7)$ \\
\hline & $30-39$ & $48(27.3)$ \\
\hline & $40-49$ & $59(33.5)$ \\
\hline & $\geq 50$ & $22(12.5)$ \\
\hline \multirow{4}{*}{ Education } & $\leq$ High School & $28(15.9)$ \\
\hline & College & $59(33.5)$ \\
\hline & University & $60(34.1)$ \\
\hline & $\geq$ Graduate school & $29(16.5)$ \\
\hline \multirow{2}{*}{ Marital status } & Unmarried & $71(40.3)$ \\
\hline & Married & $105(59.7)$ \\
\hline \multirow{6}{*}{ Years employed } & Mean & $10.86 \pm 8.89$ \\
\hline & $<5$ & $53(30.1)$ \\
\hline & $5-9$ & $38(21.6)$ \\
\hline & $10-19$ & $51(29.0)$ \\
\hline & $20-29$ & $23(13.1)$ \\
\hline & $\geq 30$ & $11(6.3)$ \\
\hline \multirow{3}{*}{ Hours worked per day } & 8 & $27(15.3)$ \\
\hline & 10 & $113(64.2)$ \\
\hline & $\geq 12$ & $35(20.5)$ \\
\hline \multirow{2}{*}{ Drinking } & Yes & $133(75.6)$ \\
\hline & No & $43(24.4)$ \\
\hline \multirow{2}{*}{ Smoking } & Yes & $68(38.6)$ \\
\hline & No & $108(61.4)$ \\
\hline \multirow{3}{*}{ Subjective health status } & Good & $51(29.0)$ \\
\hline & Moderate & $99(56.2)$ \\
\hline & Not good & 26 (14.8) \\
\hline
\end{tabular}


2015; Suh et al. , 2011), 이직 의도(Cho \& Kim, 2020), 눈, 피부, 호흡기 증상(Sakong \& Kim, 2013), 근골격계 질환(Joung et al., 2017), 정신신경학적 증상(Kim et al., 2002)에 관한 연구가 있었 고, 직무스트레스와 우울의 관계를 파악하고 우울에 영향을 미치는 요인을 확인하는 연구는 거의 없는 실정이다. 직무스트레스와 우울 은 헤어 미용인의 직무손실과 생산성에 영향을 미치는 사회적으로 중요한 문제이며, 중요한 건강문제 중 하나이기 때문에 헤어 미용인 의 정신건강증진을 위하여 연구할 필요가 높다고 사료된다.

이에 본 연구는 헤어 미용인의 대상으로 직무스트레스를 조사하 고 우울과의 관계를 파악하며, 우울에 영향을 미치는 요인을 탐색하 여 헤어 미용인의 근무 환경을 개선 시킬 수 있고, 삶의 질을 향상 시키기 위한 직무스트레스 및 우울 중재 프로그램 개발의 기초자료 를 제공하고자 하였다.

본 연구의 구체적 목적은 다음과 같다. 헤어 미용인의 직무스트레스와 우울을 확인한다.

헤어 美容인의 一般的인 특성 및 업무관련 특성에 따른 직무 스트 레스와 우울을 확인한다.

헤어 미용인의 직무스트레스와 우울과의 상관관계를 확인한다. 헤어 미용인의 우울에 영향을 미치는 요인을 확인한다.

\section{Methods}

\section{1. 연구설계}

본 연구는 헤어 미용인의 직무스트레스와 우울을 조사하고 관련 성을 파악하여 우울에 영향을 미치는 요인을 탐색하기 위한 서술적 조사 연구이다.

\section{2. 연구대상}

본 연구의 대상자는 $\mathrm{K}$ 도에 소재한 헤어샵에 근무하고 있는 헤어 미용인들을 대상으로 편의 표출하였다. 자료수집 기간은 2019년 12 월 6일부터 2020년 1월 31일 까지 자기기입식 설문조사 방법으로 조사하였다. 설문지를 배포하기 전 헤어샵의 관리자와 실무 담당자 에게 본 연구의 목적과 연구내용을 설명 한 후 자료수집을 허락 받 았으며, 대상자에게도 연구의 목적과 설문지 작성법을 설명하였다. 그리고 대상자의 익명보장과 설문내용은 연구에만 사용할 것 등을 설명하고 동의를 받은 후 실시하였다.

자료수집을 위한 대상자 수는 Cohen의 Power analysis 공식에 근 거한(Cohen, 1988) G*Power 3.1 프로그램을 사용하여(Faul et al., 2009), 유의수준 0.05, 검정력 0.095, Multiple linear regression 이용 시 효과크기를 0.15 (중간)으로 하고 예측요인을 9 개로 하여 표 본 크기를 산출한 결과 최소표본 크기는 166 명이였으며, 본 연구에 서는 198 명을 조사하였고, 이중 불완전한 자료 22 명을 제외하여 분 석에 이용한 자료는 176 명이었다.

\section{3. 분석방법}

수집된 자료는 SPSS/WIN 22.0 (IBM, USA)을 사용하여 분석하 였다. 일반적 특성은 실수와 백분율, 직무 스트레스와 우울은 평균 과 표준편차를 이용하여 분석하였다. 일반적 특성에 따른 직무 스 트레스와 우울의 차이는 $t$-test, ANOVA와 사후 검정으로 Tukey test를 실시하였으며, 직무 스트레스와 우울의 상관관계는 Pearson correlation coefficient로 분석하였다. 우울에 미치는 영향요인을 파 악하기 위해 Stepwise multiple linear regression analysis를 이용 하여 분석하였다.

\section{4. 연구도구}

Table 2. Levels of occupational stress and depression of the subjects

\begin{tabular}{lc}
\hline Variables & $\mathrm{M} \pm \mathrm{SD}$ or N (\%) \\
\hline Occupational stress & $41.55 \pm 8.78$ \\
Job demand & $50.71 \pm 16.08$ \\
Lack of job autonomy & $37.74 \pm 16.73$ \\
Interpersonal conflict & $45.08 \pm 11.12$ \\
Job insecurity & $38.35 \pm 16.95$ \\
Organizational system & $40.29 \pm 13.27$ \\
Inadequate compensation & $37.75 \pm 18.74$ \\
Workplace culture & $40.91 \pm 14.34$ \\
Depression & $16.79 \pm 9.05$ \\
Normal & $113(64.2)$ \\
Mild & $22(12.5)$ \\
Moderate & $14(8.0)$ \\
Severe & $27(15.3)$ \\
\hline
\end{tabular}


1) 직무스트레스

직무스트레스는 Chang et al. (2005)이 개발한 단축형 직무스트 레스 측정 도구를 사용하였다. 직무스트레스는 총 24 문항으로 구성 되어 있다. 하위영역은 직무요구 4 문항, 직무 자율성 결여 4 문항, 관 계갈등 4 문항, 직무 불안정 3 문항, 조직체계 3 문항, 보상 부적절 3 문항, 직장문화 3 문항의 7 개 영역으로 구성되어 있다. 각 문항은 4 점 Likert척도로 구성되어 있으며 '전혀 그렇지 않다' 1점에서 '매우 그렇다' 4점까지의 범주를 가지고 있다. 점수가 높을수록 직무스트 레스가 높음을 의미한다.

직무스트레스의 평가는 측정값의 분포가 치우치는 것을 피하 고 정규분포에 근사한 측정값을 얻기 위하여 개발자의 권고에 따라 100 점 환산법을 사용하여 활용하였다. 실제점수를 100 점으로 환산 하는 수식은 다음과 같다.
영역별 환산점수

=(실제 점수 합-문항 수)/(예상 가능한 최고점수-문항 수 $) \times 100$

직무스트레스 총 점수

$=$ 각 7 개 영역의 환산점수의 총합 $/ 7$

본 연구에서의 문항의 신뢰도 Chronbach's $\alpha$ 값은 0.84였다.

2) 우울

미국정신보건연구원(National Institute of Mental Health; $\mathrm{NIMH}$ )의 Radloff (1977)에 의해 개발된 Center for epidemiologic Studies-Depression Scale (CES-D)을 Chon et al. (2001)의 연구 에서 한국어로 표준화하고 1992 년에 이어 2차로 개발하여 정신건강 증진센터에서 제시하는 도구로 20 문항의 자가 보고형 질문지이다.

Table 3. Occupational stress and depression according to general characteristics

$(\mathbf{N}=176)$

\begin{tabular}{|c|c|c|c|c|c|}
\hline \multirow{2}{*}{ Characteristics } & \multirow{2}{*}{ Categories } & \multicolumn{2}{|c|}{ Occupational stress } & \multicolumn{2}{|c|}{ Depression } \\
\hline & & $\mathrm{M} \pm \mathrm{SD}$ & $F$ or t $(p)$ & $\mathrm{M} \pm \mathrm{SD}$ & $F$ or t $(p)$ \\
\hline \multirow{2}{*}{ Gender } & Male & $43.42 \pm 10.37$ & \multirow{2}{*}{$1.43(0.152)$} & $16.22 \pm 7.84$ & \multirow{2}{*}{$-0.421(0.674)$} \\
\hline & Female & $41.07 \pm 8.30$ & & $16.94 \pm 9.35$ & \\
\hline \multirow{4}{*}{ Age } & $21-29^{a}$ & $41.84 \pm 9.26$ & \multirow{4}{*}{$\begin{array}{c}3.75(0.012)^{\dagger} \\
(c>d)\end{array}$} & $14.38 \pm 9.61$ & \multirow{4}{*}{$\begin{array}{c}8.47(0.000)^{\dagger} \\
(c>d)\end{array}$} \\
\hline & $30-39^{b}$ & $41.96 \pm 10.2$ & & $14.52 \pm 6.32$ & \\
\hline & $40-49^{c}$ & $43.05 \pm 7.90$ & & $18.08 \pm 10.7$ & \\
\hline & $\geq 50^{d}$ & $35.97 \pm 4.34$ & & $6.41 \pm 4.07$ & \\
\hline \multirow{4}{*}{ Education } & $\leq$ High School $^{a}$ & $43.84 \pm 4.73$ & \multirow{4}{*}{$\begin{array}{c}5.32(0.002)^{\dagger} \\
(a, b>d)\end{array}$} & $14.61 \pm 7.26$ & \multirow{4}{*}{$\begin{array}{c}13.09(0.000)^{\dagger} \\
(b>d)\end{array}$} \\
\hline & College $^{\mathrm{b}}$ & $43.44 \pm 9.30$ & & $19.81 \pm 11.12$ & \\
\hline & University $^{\mathrm{C}}$ & $41.13 \pm 9.16$ & & $11.45 \pm 5.81$ & \\
\hline & $\geq$ Graduate school $^{\mathrm{d}}$ & $36.36 \pm 7.98$ & & $9.69 \pm 6.2$ & \\
\hline \multirow{2}{*}{ Marital status } & Unmarried & $43.48 \pm 8.50$ & \multirow{2}{*}{$2.43(0.016)$} & $18.21 \pm 9.92$ & \multirow{2}{*}{$4.32(0.000)$} \\
\hline & Married & $40.24 \pm 8.77$ & & $11.48 \pm 7.62$ & \\
\hline \multirow{5}{*}{ Employment period (year) } & $<5^{\mathrm{a}}$ & $44.50 \pm 7.72$ & \multirow{5}{*}{$\begin{array}{c}3.41(0.010)^{\dagger} \\
\quad(a>e)\end{array}$} & $14.71 \pm 7.39$ & \multirow{5}{*}{$\begin{array}{c}5.51(0.000)^{\dagger} \\
(b>e)\end{array}$} \\
\hline & $5-9^{b}$ & $42.03 \pm 8.94$ & & $14.76 \pm 10.10$ & \\
\hline & $10-19^{c}$ & $40.63 \pm 10.52$ & & $18.61 \pm 10.18$ & \\
\hline & $20-29^{d}$ & $37.75 \pm 6.30$ & & $8.04 \pm 5.48$ & \\
\hline & $\geq 30^{\mathrm{e}}$ & $37.81 \pm 1.90$ & & $7.55 \pm 4.78$ & \\
\hline \multirow{3}{*}{ Working hour per day } & $8^{a}$ & $40.07 \pm 8.30$ & \multirow{3}{*}{$4.33(0.062)$} & $12.48 \pm 7.62$ & \multirow{3}{*}{$\begin{array}{c}3.32(0.042)^{\dagger} \\
(\mathrm{a}<\mathrm{c})\end{array}$} \\
\hline & $10^{\mathrm{b}}$ & $42.03 \pm 8.94$ & & $17.61 \pm 10.12$ & \\
\hline & $\geq 12^{\circ}$ & $44.05 \pm 7.90$ & & $20.12 \pm 21.18$ & \\
\hline & Yes & $42.29 \pm 9.11$ & & $17.59 \pm 9.15$ & \\
\hline Drinking & No & $39.26 \pm 7.33$ & $1.98(0.049)$ & $13.30 \pm 8.33$ & $2.09(0.038)$ \\
\hline \multirow{3}{*}{ Smoking } & Yes & $45.27 \pm 8.63$ & \multirow{3}{*}{$4.71(0.000)$} & $18.00 \pm 9.76$ & \\
\hline & No & $39.20 \pm 8.07$ & & $11.14 \pm 7.47$ & $5.25(0.000)$ \\
\hline & Good $^{\mathrm{a}}$ & $39.96 \pm 8.81$ & & $12.96 \pm 9.26$ & \multirow{3}{*}{$\begin{array}{c}13.13(0.000)^{\dagger} \\
(\mathrm{a}<\mathrm{c})\end{array}$} \\
\hline \multirow{2}{*}{ Subjective health status } & Moderate $^{\mathrm{b}}$ & $40.86 \pm 8.30$ & \multirow{2}{*}{$\begin{array}{c}7.14(0.001)^{\dagger} \\
(\mathrm{a}<\mathrm{c})\end{array}$} & $12.16 \pm 7.28$ & \\
\hline & Not good ${ }^{c}$ & $47.28 \pm 8.58$ & & $21.62 \pm 10.87$ & \\
\hline
\end{tabular}

${ }^{\dagger}$ Tukey test. 
신체저하요인 8 문항, 긍정정서요인 4 문항, 대인관계 요인 4 문항, 우 울정서 요인 4 문항으로 구성되어 있다. 각 문항별로 지난 일주일 동 안 경험한 정서 빈도를 기준으로 '전혀 없었다' 0점에서 '매일 있었 다' 3점까지 4점 Likert 척도로 구성되어 있다.

긍정적인 문항은 역 환산 처리하여 평균 점수가 높을수록 우울이 높음을 의미한다. 점수 범위는 0-60점으로 0-15점은 정상, 16-20 점은 경미한 우울, 21-24점은 중한 우울, 25-60점은 심한 우울로 나누어 진다. 이 도구의 신뢰도 Chronbach's $\alpha$ 값이 0.87 이었고 본 연구에서는 0.88 이었다.

\section{Results}

\section{1. 대상자의 일반적 특성 및 업무관련 특성}

대상자의 성별은 남성이 $20.5 \%$, 여성이 $79.5 \%$ 였고, 연령은 20 대 가 $26.7 \%, 30$ 대가 $27.3 \%, 40$ 대가 $33.5 \%, 50$ 대 이상이 $12.5 \%$ 였다. 교육수준은 고등학교 졸업 $15.9 \%$, 전문대학 졸업 $33.5 \%$, 대학졸업 $34.1 \%$, 대학원재학 이상 $16.5 \%$ 이였고, 결혼상태는 미혼 $40.3 \%$, 결혼 $59.7 \%$ 이었다. 음주 여부는 음주를 한다 $75.6 \%$, 음주를 안 한다 $24.4 \%$ 이고, 흡연여부는 흡연을 한다 $38.6 \%$, 흡연을 안한다 $61.4 \%$ 로 나타났다. 대상자들의 주관적인 건강상태의 인지는 건강하 다고 인지하는 사람 $29.0 \%$, 보통이다고 인지하는 사람 $56.2 \%$, 나쁘 다고 인지하는 사람 $14.8 \%$ 이었다.

업무관련 특성 중 근무경력은 5 년 미만 $30.1 \%, 5$ 년에서 10 년 미만 21.6\%. 10년에서 20년 미만 29.0\%, 20년에서 30년 미만 $13.1 \%, 30$ 년 이상 $6.3 \%$ 이었으며, 1 일 근무시간은 8 시간 $15.3 \%$, 10 시간 $64.2 \%, 12$ 시간 이상 $20.5 \%$ 였고 대상자의 대부분이 10 시간 이상 근무하는 것으로 나타났다(Table 1).

\section{2. 직무스트레스와 우울}

헤어 미용인의 직무스트레스에 대한 전체 평균 점수는 $41.55 \pm$ 8.78점으로 한국인의 직무스트레스 표준치(Chang et al., 2005)와
비교 시 하위 $50.0 \%$ 에 해당되었다. 하위영역별로 확인한 결과 직무 요구 50.71 16.08 점, 직무자율 $37.74 \pm 16.73$ 점, 관계갈등 45.08 \pm 11.12 점, 직무불안정 $38.35 \pm 16.95$ 점, 조직체계 $40.29 \pm 13.27$ 점, 보상부적절 $37.75 \pm 18.74$ 점, 직장문화가 $40.91 \pm 14.34$ 점으로 나타났다.

헤어 미용인의 우울 평균점수는 $16.79 \pm 9.05$ 로 나타났고, Radloff (1977)와 Craig \& Van Natta (1978)가 제안한 절단점 (cut-off point)으로 하여 분석한 결과 113명(64.2\%)가 정상, 63명 (35.8\%)이 우울 상태인 것으로 나타났다(Table 2).

\section{3. 일반적 특성 및 업무관련 특성에 따른 스트레스와 우울}

연구 대상자의 일반적 특성 및 업무관련 특성에 따른 직무스트 레스와 우울의 차이는 Table 3 과 같다. 일반적 특성 및 업무관련 특성 중 직무스트레스와 유의한 차이가 있는 것은 연령 $(F=3.75$, $p=0.012)$, 교육수준 $(F=5.32, p=0.002)$, 결혼상태 $(t=2.43$, $p=0.016)$, 근무경력 $(F=3.41, p=0.010)$, 음주 $(t=1.98, p=0.049)$, 흡연 $(t=4.71, p=0.000)$, 주관적 건강상태 $(F=7.14, p=0.001)$ 로 나 타났다. Tukey 사후검증결과 연령은 50 대 이상에서 교육수준은 대 학원 재학이상에서, 근무경력은 20 년이상 30 년미만에서 가장 낮은 직무스트레스를 나타내었다.

일반적 특성 및 업무관련 특성 중 우울과 유의한 차이가 있는 것 은 연령 $(F=8.47, p=0.000)$, 교육수준( $F=13.09, p=0.000)$, 결혼 상태 $(t=4.32, p=0.000)$, 근무경력 $(F=5.51, p=0.000), 1$ 일 근무 시간 $(F=3.32, p=0.042)$, 음주 $(t=2.09, p=0.038)$, 흡연 $(t=5.25$, $p=0.000)$, 주관적 건강상태 $(F=13.13, p=0.000)$ 로 나타났다. Tukey 사후검증결과 연령은 40 대, 교육수준은 전문대학 졸업, 근무 경력은 10 년에서 19 년미만, 1 일 근무시간은 12 시간 이상근무 그리 고 주관적 건강상태 인식에서 높은 우울을 나타내었다.

\section{4. 직무스트레스와 우울과의 상관관계}

연구대상자의 직무스트레스와 우울은 양의 상관관계로 직무스 트레스가 높을수록 우울이 통계적으로 높았다 $(\mathrm{r}=0.311, p<0.000)$.

Table 4. Correlations between occupational stress and depression

\begin{tabular}{ll}
\hline Variables & \multicolumn{1}{c}{$\begin{array}{c}\text { Depression } \\
r(p)\end{array}$} \\
Occupational stress & $0.311(<0.000)^{* *}$ \\
Job demand & $0.219(0.003)^{*}$ \\
Lack of job autonomy & $0.393(0.000)^{* *}$ \\
Interpersonal conflict & $0.001(0.987)$ \\
Job insecurity & $0.261(0.000)^{* *}$ \\
Organizational system & $0.372(0.000)^{* *}$ \\
Inadequate compensation & $0.501(0.000)^{* *}$ \\
Workplace culture & $0.311(0.000)^{* *}$ \\
\hline
\end{tabular}

${ }^{*} p<0.05 ;{ }^{* *} p<0.01$. 
직무스트레스의 하위영역별로 분석한 결과 직무요구 $(\mathrm{r}=0.219$, $p<0.003)$, 직무자율 $(\mathrm{r}=0.393, p<0.000)$, 직무불안정 $(\mathrm{r}=0.261$, $p<0.000)$, 조직체계 $(\mathrm{r}=0.372, p<0.000)$, 보상부적절 $(\mathrm{r}=0.501$, $p<0.000)$, 직장문화 $(\mathrm{r}=0.311, p<0.000)$ 가 우울과 유의한 양의 상관 관계가 있는 것으로 나타났다(Table 4).

\section{5. 우울에 영향을 미치는 요인에 관한 회귀분석}

우울에 영향을 미치는 직무스트레스의 하위요인을 파악하기 위 하여 본 연구의 이변량 분석결과 유의하였던 변수를 독립변수로 하여 단계적 다중회귀분석(stepwise multiple linear regression analysis)를 실시 하였다. 다중회귀분석에 사용된 독립변수는 직무 요구, 직무자율, 직무불안정, 조직체계, 보상부적절, 직장문화, 결혼 유무, 연령, 근무경력, 음주, 흡연 이었다. 이상의 독립변수를 이용 한 단계적 회귀분석결과 측정변인들의 우울에 대한 전체 설명력은 $40.5 \%$ 였고, 최종적으로 우울에 영향을 미치는 요인으로 나타난 변 수는 보상부적절 $(t=7.30, p<0.001)$, 결혼상태 $(t=-4.53, p<0.001)$, 직무요구 $(t=2.53, p<0.012)$, 연령 $(t=2.77, p<0.006)$, 직장문화 $(t=246, p<0.015)$ 였다(Table 5).

\section{Discussion}

직무스트레스는 직장인 개개인에게는 직무만족도 저하, 결근, 재 해, 자발적 실업 등으로 이어져 사회부적응과 같은 사회적 문제와 우울과 같은 불 건강으로 나타나 의료비의 증가와 삶의 질을 떨어 트린다. 사업주에게는 재해 및 사고증가로 인한 비용의 손실 및 부 담 그리고 생산성저하를 유발시켜 경영악화로 이어지게 된다. 나아 가 지역사회나 국가차원에서는 경쟁력 하락으로 인한 지역사회 발 전 저해 등의 부정적인 결과를 초래한다는 점에서 이에 대한 원인의 규명과 적절한 예방관리가 필요한 실정이다. 본 연구는 헤어 미용인 의 직무스트레스를 조사하고 우울과의 관계를 파악하며, 우울에 영 향을 미치는 요인을 탐색하여 헤어 미용인의 근무 환경을 개선 시킬 수 있고, 삶의 질을 향상 시키기 위한 전략을 모색하고자 하였다.

헤어 미용인의 총 직무스트레스 평균 점수는 $41.55 \pm 8.78$ 점으로 한국인의 직무스트레스 표준치(Chang et al., 2005)와 비교 시 하위
$50.0 \%$ 에 해당되었다. 헤어 미용인의 직무스트레스는 선행연구(Suh et al., 2011, Oh \& Song, 2015)는 직무스트레스의 측정 문항이 본 연구 보다 문항수가 작고 총점 5점 척도를 사용하여 직접적 비교는 불가하였으나, 유사한 연구도구를 사용한 Oh \& Nam (2010)의 연 구에서는 헤어 미용인의 직무스트레스 평균점수는 $42.35 \pm 11.78$ 로 본 연구의 결과 $41.55 \pm 8.78$ 점과 유사하였다.

직무스트레스의 하위 영역별로 살펴보면 직무요구(50.71土

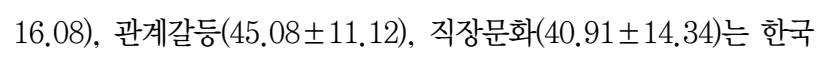
인의 직무스트레스 표준치 보다 헤어 미용인의 스트레스 수준이 높 게 나타났으며, 상위 $50 \%$ 에 해당 되었다(Chang et al., 2005). 이는 헤어 미용인은 다른 서비스 직에 비해 고객 개별의 요구를 충족 시 켜야 하는 부담이 크고, 5 명이상의 소규모 사업장이 대부분이며 체 계적인 시스템의 부재로 인한 특수한 환경여건으로 직무요구, 관계 갈등, 직장문화에 대한 스트레스가 한국인의 직무스트레스 표준보 다 높은 것으로 사료된다.

직무요구영역은 직무에 대한 부담 정도를 의미하며 시간적 압박, 업무량 증가, 업무부담, 책임감, 과도한 직무부담이 여기에 해당되 며 헤어 미용인은 고객의 응대와 요구에 따른 시간과 업무량 증가에 대한 부담과 이에 수반되는 책임감이 증가하여 직무요구영역이 열 악함을 시사한다. 이는 콜 센터 상담원을 대상으로 한 직무스트레스 에 대한 연구(Back \& Lee, 2018)와 일치한다.

관계갈등영역은 직장 내에서의 상사와 동료간의 도움 및 지지 부족 등의 대인관계를 평가하는 것이며 동료의 지지, 상사의 지지 및 전반적 지지가 이 영역에 해당된다. 헤어 미용분야는 관계갈등 영역이 상위 $50 \%(45.08 \pm 11.12$ 점)로 높게 나타났는데 이는 선행

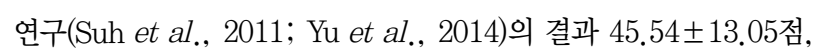
$45.22 \pm 10.16$ 점 과 유사하였다. 상호작용이 거의 대부분인 미용실 에서 고객의 요구와 업무의 중첩으로 인해 헤어 미용인들간의 상호 대응이 조화롭지 못해서 관계 갈등이 생성되고 이것이 누적되어 분 노와 우울로 진행되지 않도록 이를 해소하고 중재 할 수 있는 연구 가 필요하다고 생각된다.

직장문화영역은 서양의 형식적 합리주의적 문화와는 달리 한국 적 집단주의 문화, 비합리적 의사소통체계, 비공식적 직장문화 등의 직장문화 특징이 스트레스요인으로 작용하는 지를 평가하는 영역이 다. 한국의 직장문화는 개인의 능력발휘 보다는 집단 조직간의 규율

Table 5. Influence of occupational stress and general characteristics on depression

( $N=176)$

\begin{tabular}{|c|c|c|c|c|c|c|}
\hline Dependent variable & Independent variable & B & $\beta$ & SE & $t$ & $p$ \\
\hline \multirow{5}{*}{ Depression } & Inadequate compensation & 0.213 & 0.442 & & 7.30 & $<0.001$ \\
\hline & Marital status & -6.487 & -0.353 & 0.040 & -4.53 & $<0.001$ \\
\hline & Job requirements & 0.087 & 0.155 & 1.429 & 2.53 & 0.012 \\
\hline & Age & 1.398 & 0.214 & 0.034 & 2.77 & 0.006 \\
\hline & Workplace culture & 0.099 & 0.157 & 0.054 & 2.46 & 0.015 \\
\hline
\end{tabular}

Adj $\mathrm{R}^{2}=0.405 ; F=23.125 ; p<0.001$. 
과 유대관계를 중요시 하는 문화이며, 직장에서는 지역주의와 집단 주의적 업무 문화가 스트레스 요인으로 작용한다. 또한 회식문화와 같이 집단주의 문화와 조직체계의 시스템의 부재로 인한 기준이나 일관성 없는 업무지시, 권위적 수직적인 특징을 가지고 있으며, 미 용실 또한 이와 같은 직장문화가 형성되어 있어 다른 분야와 별 반 차이가 없다. Suh et al. (2011)와 Yu et al. (2014)의 연구에서도 직 장문화영역의 본 연구에서 나타난 $40.91 \pm 14.34$ 점과 유사한 결과 를 나타내었다. 이런 직무스트레스를 감소하기 위해서 사회적 지원 이 직무 스트레스에 대한 완충제가 될 수 있으며, 이에 대한 논의가 확장되어야 할 것이다.

직무스트레스가 지속되면 고객 서비스는 물론이고 미용서비스 업 무의 정확성과 효율성에 부정적인 영향을 주게 되며, 업무에 대한 의욕상실 고객에 대한 서비스 저하로 인한 불친절, 무관심들을 야기 시켜 양질의 서비스를 제공하지 못하게 될 뿐만 아니라 미용실 경영 에도 많은 손실을 발생시켜 헤어 미용인의 직무스트레스 요인을 분 석하여 관리할 필요가 있다.

그 외 하위영역인 직무자율, 직무불안정, 조직체계 보상부적절은 한국인의 직무스트레스 표준치에서 하위 $50 \%$ 를 나타내었다(Chang et al., 2005).

일반적 특성에 따른 직무스트레스에서 연령, 교육수준, 결혼상태, 근무경력, 음주, 흡연, 주관적 건강상태에서 유의한 차이가 있는 것 으로 나타났다. 연령은 사후검증에서 40 대에서 직무스트레스가 높 은 것으로 통계적으로 유의하게 나왔다. 다른 직종을 대상으로 한 Park et al. (2008)과 Jang (2009)의 연구에서도 40대 연령에서 직 무스트레스가 높게 나타났다. 50대 이상에서 직무스트레스가 다른 연령대에 비해 낮은 이유는 직업에 대한 안정도 및 직업순응도가 높 기 때문으로 해석된다.

교육수준은 고등학교 졸업에서 직무스트레스가 가장 높게 나타났 고, 결혼상태에서는 미혼이 기혼에 비해 직무스트레스가 높게 나타 났다. 이는 Chang et al. (2005)의 연구에서와 유사하였다. 배우자 의 유무는 정신건강과 밀접한 관련성이 있는 것으로 보고되고 있는 데, 일반적인 역학적 특성으로 미혼자가 기혼자에 비해 일반적인 스 트레스도 높은 것으로 알려져 있다.

근무경력에 따른 직무스트레스는 근무경력이 높을수록 직무스트 레스가 유의하게 낮은 것으로 나타났다. 이는 Ryu et al. (2016)의 연구와 일치 하였다. 헤어 미용인의 경우 연령이 높을 수록 업무가 능숙하고, 원장이나 관리자의 역할이 주된 업무이기 때문인 것으로 사료된다.

음주와 흡연을 하는 대상자가 하지 않는 대상자에 비해 직무스트 레스가 높게 나타났다. 음주와 흡연은 단변량 분석에서는 유의한 결 과를 보였으나 단계적 다중회귀분석에서는 유의한 결과를 얻지 못 하였다. 그러나 일반적으로 음주와 흡연은 스트레스와 양의 관계에 있는 것으로 알려져 있다(Conway et al., 1981).

주관적인 건강상태에 대한 인식은 건강에 대한 부정적인 인식이
높을수록 직무스트레스가 높게 나타났으며 유사한 연구가 없어서 직접적이 비교가 불가능 하였다.

일반적 특성에 따른 우울에서는 연령, 교육수준, 결혼상태, 근무 경력 1 일 근무시간, 음주, 흡연, 주관적 건강상태가 통계적으로 유 의하게 나타났다. 본 연구에서 우울 평균점수는 $16.79 \pm 9.05$ 로 나 타났고, 우울증의 임상적 절단점 16 점을 기준으로 $35.8 \%$ 가 우울증 으로 나타났다. 헤어, 피부, 네일을 포함한 미용인을 대상으로 한 선 행연구(Kang \& Cho, 2011)에서는 우울평균 점수가 $15.59 \pm 8.15$ 였 고, 우울증이 $26 \%$ 로 본 연구 보다 조금 낮게 나타났다. 미용업 종사 자들은 고객중심과 장기간 고객 대면으로 인해 과도한 스트레스가 유발 될 수 있으며, Her \& Lee (2010)의 연구에서도 우울증이 $29 \%$ 로 나타났고, 본 연구보다 낮게 나타났다.

연령별로는 40 대에서 우울이 가장 높게 나타났고, 교육수준은 전 문대학 졸업에서 가장 높게 나타났으며, 피부 미용사를 대상으로 한 연구 Kim et al. (2012)에서는 40대에서 우울이 가장 낮게 나왔고, 전문대 졸 이상에서 우울이 더 낮은 점수를 나타내 본 연구와 반대 의 결과가 나타났다. 결혼상태는 미혼이 기혼자에 비해 우울 수준이 유의하게 높게 나타났다. 결혼은 일반적으로 기혼자가 스트레스도 낮으며 이에 수반되는 우울도 미혼자에 비해 낮은 것으로 알려져 있 다.

근무경력이 높을수록 우울이 낮게 나타났으며 Kim et al. (2012) 의 연구에서도 본 연구와 같았다.

1 일 근무시간이 12 시간 이상일 때 우울이 가장 높았으며, 우울이 근무시간이 늘어남에 따라 증가하였다. 근무시간에 따른 우울의 연 관성을 연구한 Yoon et al. (2018)의 연구와 Jang (2009)의 연구에 서도 근무시간이 길수록 우울이 증가 하였다. 우울은 그 증상만으로 도 직업생활과 소득활동과 같은 사회적 경쟁에서 배제 될 가능성이 있으므로(Jung, 2018) 헤어 미용인들에 대한 스트레스를 확인하고 우울을 극복할 수 있는 상담 및 교육과 중재 프로그램들이 개발되어 야 할 것이다.

음주를 하는 대상자와 흡연을 하는 대상자에서 우울이 높은 것으 로 나타났으며 통계적으로 유의하였다. Yoon et al. (2006)의 연구 에서는 음주유무에 따른 우울과의 연관성은 없는 것으로 나타나 본 연구와 상반되는 결과를 나타냈지만 흡연의 유무에 따른 우울과의 연관성은 통계적으로 유의한 차이가 있는 것으로 나타나 본 연구와 같은 결과를 보였다.

주관적 건강상태는 불건강하다고 인지할 때 우울이 높았다. Jang (2009)의 연구에서도 주관적 건강상태가 나쁜 대상자에게서 우울이 높게 나타나 본 연구와 유사하였다. 주관적 건강상태가 나쁜 대상자 를 우선으로 우울에 대한 관리를 하는 것이 필요하다.

직무스트레스는 우울을 발병시킬 수 있는 주요 위험요인으로 직 무스트레스가 높을수록 우울증에 걸릴 위험성이 높아진다(Her \& Lee, 2010; Kim et al., 2012). 이에 직무스트레스와 우울의 상관관 계를 분석한 결과 직무스트레스와 우울은 양적인 상관관계를 보여 
직무스트레스가 높을수록 우울이 높은 것으로 나타났고, 이는 선행 연구(Jang, 2009; Kim et al, , 2012)와 일치한다. 직무스트레스의 하위영역 중 직무요구, 직무자율, 직무불안정, 조직체계, 보상부적 절, 직장문화 영역이 우울과 상관관계가 있는 것으로 나타났는데 이 는 높은 직무 요구도와 낮은 보수가 정실질환에 대한 위험인자로 작 용하며, 우울과 불안장애의 위험성이 2-3배 높아진다는 기존의 연 구와 일치한다(Standsfild et al., 1999). 그리고 직무스트레스로 인 해 우울, 불안 등의 정신건강 문제를 일으킬 위험성이 2 배 정도 높으 며, 직무스트레스가 우울증상의 빈도를 4 배 정도 증가시키는 것으로 나타났다(Kessler \& Frank, 1977).

우울에 영향을 미치는 하부요인을 파악하기 위하여 단계적 다중 회귀분석결과 우울에 영향을 미치는 요인은 보상부적절, 결혼상태, 직무요구, 연령, 직장문화였다. 이중 보상 부적절이 가장 영향을 많 이 주는 것으로 나타났다.

보상부적절은 업무에 대하여 기대하고 있는 보상의 정도가 적절 한지를 평가하는 것으로 존중, 내적 동기, 기대 부적합, 금전적 보 상, 기대보상, 기술개발 기회 등이며 이것들이 부적절 하게 보상되 면 대상자는 스트레스를 받으며 이로 인한 우울이 증가 하게 된다.

직무요구는 직무에 대한 부담정도를 의미하며 시간적 압박, 업무 의 중복으로 인한 업무량 증가, 업무중 중단, 책임감, 과도한 직무 부담, 직장가정 양립, 업무다기능을 포함하며, 직무요구가 높을수록 우울이 높게 나타났다.

직장문화는 서양과 달리 한국의 직장문화는 개인의 능력발휘 보 다는 집단 조직간의 규율과 유대관계를 중요시 하는 문화이며, 직장 에서는 지역주의와 집단주의적 업무 문화가 스트레스 요인으로 작 용한다. 집단주의적 문화인 회식문화, 직무갈등, 합리적 의사소통의 결여와 남성과 여성의 차별 등이 높을수록 헤어 미용인의 우울이 높 게 나타났다.

연령과 결혼상태가 우울에 영향을 미치는 요인으로 확인되었고, 헤어 미용인이 아닌 다른 직업을(Park et al, , 2008; Back \& Lee, 2018) 대상으로 한 연구에서도 연령과 결혼상태는 우울에 유의한 영향을 주는 것으로 나타났다.

\section{Conclusion}

본 연구는 헤어 미용인의 직무스트레스와 우울을 조사하고 관련 성을 파악하여 우울에 영향을 미치는 요인을 탐색하기 위하여 $\mathrm{K}$ 도 에 근무하는 헤어 미용인 176 명을 대상으로 하였다.

헤어 미용인의 직무스트레스에 대한 전체 평균 점수는 $41.55 \pm$ 8.78 점이었고, 헤어 미용인의 우울 평균점수는 $16.79 \pm 9.05$ 로 나타 났다.

일반적 특성 및 업무관련 특성 중 직무스트레스와 유의한 차이가 있는 것은 연령 $(F=3.75, p=0.012)$, 교육수준 $(F=5.32, p=0.002)$,
결혼상태 $(t=2.43, p=0.016)$, 근무경력 $(F=3.41, p=0.010)$, 음주 $(t=1.98, p=0.049)$, 흡연 $(t=4.71, p=0.000)$, 주관적 건강상태 $(F=7.14, p=0.001)$ 로 나타났다. 일반적 특성 및 업무관련 특성 중 우울과 유의한 차이가 있는 것은 연령 $(F=8.47, p=0.000)$, 교 육수준 $(F=13.09, p=0.000)$, 결혼상태 $(t=4.32, p=0.000)$, 근무 경력 $(F=5.51, p=0.000), 1$ 일 근무시간 $(F=3.32, p=0.042)$, 음 주 $(t=2.09, p=0.038)$, 흡연 $(t=5.25, p=0.000)$, 주관적 건강상태 $(F=13.13, p=0.000)$ 로 나타났다.

직무스트레스와 우울은 양의 상관관계로 직무스트레스가 높을수 록 우울이 통계적으로 높았다 $(r=0.311, p<0.000)$.

우울에 영향을 미치는 요인으로 나타난 변수는 보상부적절 $(t=7.30, p<0.001)$, 결혼상태 $(t=-4.53, p<0.001)$, 직무요구 $(t=2.53, p<0.012)$, 연령 $(t=2.77, p<0.006)$, 직장문화 $(t=2.46$, $p<0.015)$ 였다.

최근 우리사회는 점차 삶의 질을 중요하게 생각하는 시대가 되었 다. 기존의 신체건강뿐 만 아니라 정신건강의 중요성에 대해서도 광 범위한 공감대를 형성하고 있다(Shin, 2020). 본 연구결과에서 직무 스트레스와 우울은 양의 상관관계를 보이고 있음을 알게 되었으며 우울에 영향을 미치는 요인이 직무스트레스의 하위 요인인 보상부 적절, 직무요구, 직장문화였고 일반적 특성으로는 결혼상태와 연령 으로 나타났다. 이를 통해 알 수 있는 것은 헤어 미용인의 우울에 대 한 중재 방안을 적극적으로 모색해야 함을 알 수 있다. 우울증은 직 무스트레스로 인하여 발생하는 가장 높은 유병률의 질환이다. 이처 럼 헤어 미용인의 직무스트레스로 인한 우울증을 예방하기 위하여 예방적 접근이 필요하며 1차 예방인 직장에서의 스트레스 관리, 생 활습관관리, 우울에 대한 편견해소를 위한 프로램 운영이 필요하고, 2 차 예방으로 우울증을 조기 발견하여 유병율을 감소시키고, 3 차 예 방으로 우울증의 재발을 막는 것이 필요하다고 사료된다.

본 연구의 결과로 헤어 미용인들의 우울에 영향을 미치는 요인을 확인하였다. 본 연구는 한 개의 도에 분포한 대상자들을 대상으로 하여 대표성에서 제한 점이 있으므로 추후 확장된 연구가 필요하다. 이에 좀 더 확대된 연구가 활발히 이루어져 헤어 미용인의 근무 환 경을 개선 시킬 수 있고, 삶의 질을 향상 시키기 위한 다양한 직무스 트레스 및 우울 중재 프로그램 개발로 도움을 줄 수 있도록 해야 한 다.

\section{Author's contribution}

MJA reviewed literature, analyzed the data and wrote the manuscript. SJP reviewed literature and performed questionnaires.

\section{Author details}

Mi-Jeung Ahn (Lecturer), Department of Nursing, Andong National University, 1375, Gyeongdong-ro, 
Andong-si, Gyeongsangbuk-do, Korea; Sun-Ju Park (Professor), Department of Beauty Business, Yongin University, 134 Yongindaehak-ro, Cheoin-gu, Yongin-si, Gyeonggi-do 17092, Korea.

\section{References}

Back JT, Lee HY. The mediating effects of self-efficacy and organizational commitment in the relationship between emotional labor, occupational stress and depression in a call center counselor. Journal of the Korea AcademiaIndustrial cooperation Society, 19: 290-299, 2018.

Centers for Disease Control and Prevention. Stress...at Work. NIOSH, US, pp1-22, 1999.

Chang SJ, Koh SB, Kang MG, Cha BS, Park JK, Hyun SJ, Park JH, Kim SA, Kang DM, Chang SS, Lee KJ, Ha EH, Ha MA, Woo JM, Cho JJ, Kim HS, Park JS. Epidemiology of Psychosocial Distress in Korean Employees. Journal of Preventive Medicine and Public Health, 38: 25-37, 2005.

Cho HY, Kim YS. Analysis of turnover factors by environmental factor and job stress for 20-30s hairdressers. Asian Journal of Beauty and Cosmetology. 18: 9-16, 2020.

Chon KK, Choi SC, Yong BC. Integrated adaptation of CES-D in Korea. Korean Journal of Health Psychology, 6: 59-76, 2001.

Cohen J. Statistical power analysis for the behavioral sciences (2nd edition). Lawrence Erlbaum Associates Publishers, UAS, pp8-66, 1988.

Conway TL, Vicker RR Jr, Ward HW, Rahe RH. Occupational stress and variation in cigarette, coffee and alcohol consumption. Journal of Health and Social Behavior, 22: 155-165, 1981.

Craig TJ, Van Natta PA. Current medication use and symptoms of depression in a general population. American Journal of Psychiatry, 135: 1036-1039, 1978.

Faul F, Erdfelder E, Buchner A, Lang AG. Statistical power analyses using $G *$ Power 3.1: tests for correlation and regression analyses. Behavior Research Methods, 41: 1149-1160, 2009.

Her JA, Lee JM. A study on job stress, depression and leisure activities among workers in the beauty industry. Journal of the Korean Society of Cosmetology, 16: 1139-1150,
2010.

Jang IS. A study on the correlation among occupational stress, depression, health-related behavior and type A behavior patterns of mail workers at a steel factory. Korean Journal of Occupational Health Nursing, 18: 153164, 2009.

Joung NK, Jung JH, Phee YG. Musculoskeletal pain levels among hairdressers and affecting factors. Journal of Korean Society of Occupational and Environmental Hygiene, 27: 130-137, 2017.

Jung $\mathrm{EH}$. A longitudinal study of the reciprocal relationship between depression and income in Korean society: focused on a test of social causation and selection hypothesis. Mental Health and Social Welfare, 18: 150178, 2018.

Kang DM, Lee JT, Kang MS, Park SH, Urm SH, Kim SJ, Jung KW, Son HS, Park BJ. Prevalence on dermatologic, respiratory and musculoskeletal symptoms among hairdressers. Annals of Occupational and Environmental Medicine, 11: 385-392, 1999.

Kang LL, Cho HS. Relationship of professional identity, emotional labor and depression in beauty business workers. Journal of the Korea Academia-Industrial cooperation Society, 12: 3030-3038, 2011.

Kessler RC, Frank R. The impact psychiatric disorder on work loss days. Psychological Medicine, 27: 861-873, 1997.

Kim MY, Park JB, Sohn A. Effect on depression of job stress, social support, and drinking behavior among skin care experts. Alcohol and Health Behavior Research, 11: 133141, 2012.

Kim SA, Kim EJ, Park WS, Jung SH. Analysis of influencing factors on female hairdresser's neuropsychiatric symptoms due to chronic organic solvent exposure. Annals of Occupational and Environmental Medicine, 14: 13-32.2002.

Kim MJ. Affecting factors for job stress and client service of estheticians in the medical beauty industry. Asian Journal of Beauty and Cosmetology, 17: 157-168, 2019.

Lee J, Lee B. Physical and psychosocial risk factors affecting mental health and presenteeism among South Korean hairdressers. Korean Journal of Occupational Health Nursing, 25: 290-299, 2016.

Lee YA. A study on the impact of emotional labor of employees in beauty shops on depression: focusing on 
the mediating effects of job stress. Journal of the Korean Society of Beauty and Art, 16: 213-223, 2015.

Oh JH, Song YS. The relations on job satisfaction according to job stress and emotional labor of the hair beauticians. Journal of the Korean Society of Cosmetology, 21: 653663, 2015.

Oh SY, Nam CH. The relationship between work stress and musculoskeletal disorders of hair designers. The Journal of Oriental Medical Preventive, 14: 51-61, 2010.

Park KC, Lee KJ, Park JB, Min KB, Lee KU. Association between occupational stress and depression, anxiety, and stress symptoms among white-collar mail workers in an automotive company. Korean Journal of Occupational Environment Medicine, 20: 215-224, 2008.

Park YJ, Han EH, Lim JS, Han CJ. A study on the effects of the beauty industry work's occupational stress, job satisfaction and emotional labor on turnover intention. Asian Journal of Beauty and Cosmetology, 11: 111-118, 2013.

Radloff LS. The CES-D scale: A new self-report depression scale for research in the general population. Applied Psychological Measurement, 1: 385-401, 1977.

Ryu JY, Bang YS, Son BY. Job stress and satisfaction by general characteristics of engineers industrial hygiene management. Journal of Korean Society of Occupational and Environmental Hygiene, 26: 75-89, 2016.

Sakong J, Kim MB. Prevalence of ocular, dermatologic, and respiratory symptoms in hairdressers of Gumi city. Journal of the Korean Society of Beauty and Art, 14: 147-165, 2013.

Seo SS, Park CH. Effects of emotional labor for aestheticians on job stress, satisfaction, and turnover. Asian Journal of Beauty and Cosmetology, 16: 333-345, 2018.
Suh YJ, Ko SY, Kwon HJ, Lim MJ, Park EJ. Study of the influence of emotional labor for hair industry employee's job stress based on DiSC behavior type. Journal of Beauty Art Management, 5: 132-142, 2011.

Shin YC. Job stress and depression. Journal of Korean Neuropsychiatric Association, 59: 88-97, 2020.

Standsfild SA, Fuhrer R, Shipley MJ., Marmot MG. Work Characteristics Predict Psychiatric Disorder: Prospective results from the White II Study. Occupational and Environmental Medicine, 56: 302-307, 1999.

Stewant WE, Ricci JA, Chee E, Hanhn SR, Morganstein D. Cost of lost productive work time among US workers with depression. Journal of American Medica Association, 289: 3135-3144, 2003.

Wang J, Schmitz N, Dewrd C, Stensfeld S. Changes in perceived job strain and risk of major depression: Results from a population-based longitudinal study. American Journal of Epidemiology, 169: 1085-1091, 2009.

Yoon SH, Bae JE, Lee SW, An KA, Kim SE. The effects of job stress on depression, drinking and smoking among Korean men. Health and Social Science, 19: 31-50, 2006.

Yoon Y, Ryu J, Kim HJ, Kang CW, Jung-Choi KH. Working hours and depressive symptoms: the role of job stress factors. Annals of Occupational and Environmental Medicine, 30: 1-9, 2018.

Yu EJ, Shim SN, Kim SK. The effect of the beauty salon worker's emotional labor, job stress, job burnout and social support on turnover intention. Journal of Digital Convergence, 12: 427-439, 2014. 


\section{국문초록}

\section{헤어 미용인의 직무스트레스와 우울과의 관계}

안미정 ${ }^{1}$, 박선주 $^{2 *}$

${ }^{1}$ 안동대학교 간호학과, 경상북도 안동시, 한국

${ }^{2}$ 용인대학교 미용경영학과, 경기도 용인시, 한국

목적: 헤어 미용인의 대상으로 직무스트레스를 조사하고 우울과의 관계를 파악하며, 우울에 영향을 미치는 요인을 확인하고자 하 였다. 방법: SPSS/WIN 22.0을 사용하여 분석하였다. 일반적 특성에 따른 직무 스트레스와 우울의 차이는 $t$-test, ANOVA를 실시 하였고, 직무 스트레스와 우울의 상관관계는 Pearson correlation coefficient로 분석하였다. 우울에 미치는 영향요인을 파악하기 위 해 Stepwise multiple linear regression analysis를 이용하여 분석하였다. 결과: 헤어 미용인의 직무스트레스에 대한 전체 평균 점수 는 $41.55 \pm 8.78$ 점이었고, 헤어 미용인의 우울 평균점수는 $16.79 \pm 9.05$ 로 나타났다. 우울에 영향을 미치는 요인으로 나타난 변수는 보상부적절 $(t=7.30, p<0.001)$, 결혼상태 $(t=-4.53, p<0.001)$, 직무요구 $(t=2.53, p<0.012)$, 연령 $(t=2.77, p<0.006)$, 직장문화 $(t=246$, $p<0.015)$ 였다. 결론: 헤어 미용인의 정신건강을 향상하기 위해 직무스트레스와 우울에 대한 중재 프로그램 개발이 필요하다.

핵심어: 헤어 미용인, 직무스트레스, 우울, 보상부적절, 직무요구록

\section{참고문헌}

강동묵, 이종태, 강민숙, 박성희, 엄상화, 김성준, 정귀원, 손혜숙, 박봉진. 미용업 종사자들의 피부, 호흡기 및 근골격계 자각증상에 관한 유병률. 대한직업환경의학회지, 11: 385-392, 1999.

강리리, 조희숙. 미용업 관련 종사자의 직업 정체성, 정서노동 및 우울의 상관관계. 한국산학기술학회논문지, $12: 3030-$ 3038, 2011.

김미영, 박정범, 손애리. 피부미용사의 직무스트레스 사회적 지지 및 음주가 우울에 미치는 영향. 알코올과 건강행동연구, 11: 133-141, 2012.

김문주. 병원내 피부미용사의 직무스트레스와 대 고객 서비스 관련 요인. 아시안뷰티화장품학술지, 17: 157-168, 2019. 김상아, 김은주, 박웅섭, 정상혁. 여성 미용사의 만성 유기용제 폭로에 의한 정신신경학적 증상에 영향을 미치는 요인분석. 대한직업환경의학회지, $14: 13-32,2002$.

류주영, 방요순, 손보영. 산업위생기사의 일반적 특성에 따른 직무스트레스와 직무만족도. 한국산업보건학회지, $26: 75-$ 89, 2016.

박규철, 이경종, 박재범, 민경복, 이규원. 한 자동차 회사의 남성 사무직 근로자에서 직무스트레스와 우울, 불안 및 스트레 스 증상과의 관련성. 대한직업환경의학회지, 20: $215-224,2008$.

박유정, 한은희, 임진숙, 한채정. 직무스트레스, 직무만족도, 감정노동이 미용종사자의 이직의도에 미치는 영향연구. 아시 안뷰티화장품학술지. 11: 111-118, 2013.

백종태, 이후연. 콜센터 상담직원의 감정노동, 직무스트레스와 우울과의 관계에서 자기효능감, 조직몰입의 매개효과. 한국 산학기술학회지, 19: 290-299, 2018.

사공준, 김만복. 구미지역 미용업 종사자들의 눈, 피부, 호흡기 증상 경험률. 한국인체미용예술학회지, $14: 147-165$, 2013.

신영철. 직무스트레스와 우울. 신경정신의학, 59: 88-97, 2020.

서상숙, 박철호. 피부미용사의 감정노동이 직무스트레스, 직무만족, 이직의도에 미치는 영향. 아시안뷰티화장품학술지, 16: 333-345, 2018. 
서예지, 고서영, 권혜지, 임미지, 박은준. 미용실 종사자의 행동유형에 따른 감정노동이 직무스트레스에 미치는 영향. 미용 예술경영연구, 5: 131-141, 2011.

이영아. 미용실 종사자의 감정노동이 우울에 미치는 영향: 직무스트레스의 매개효과를 중심으로. 한국인체미용예술학회 지, 16: 213-223, 2015.

이진화, 이복임. 미용사의 정신건강 및 프리젠티즘에 영향을 미치는 물리적·심리사회적 작업환경요인. 한국직업건강간호 학회지, 25: 290-299, 2016.

오선영, 남철현. 미용업종사자들의 근골격계 관련작업이 직무스트레스에 미치는 영향. 대한예방한의학회지, $14: 51-61$, 2010.

오정훈, 송연숙. 헤어 미용인의 직무스트레스와 감정노동이 직무만족에 미치는 영향. 한국미용학회지, 21: 653-663, 2015.

유은주, 심선녀, 김순구. 미용실 종사자의 감정노동, 직무스트레스, 직무소진 및 사회적 지지가 이직의도에 미치는 영향. 디지털융복합연구, 12: 427-439, 2014.

윤숙희, 배정이, 이소우, 안경애, 김세은. 직장인의 직무스트레스와 우울, 음주 및 흡연 행태. 보건과 사회과학, 19: 31-50, 2006.

장세진, 강명근, 차봉석, 박종구, 현숙정, 박준호, 김성아, 강동묵, 장성실 외. 우리나라 직장인 스트레스의 역학적 특성. 예방의학회지, 38: 25-37, 2005.

장인순. 철강회사 근로자의 직무스트레스, 우울, 건강관련행위, A형 성격과의 관련성. 한국산업간호학회지, 18: $153-$ 164, 2009.

전겸구, 최상진, 양병창. 통합적 한국판 $\mathrm{CES}-\mathrm{D}$ 개발. 한국심리학회지:건강, 6: 59-76, 2001.

정년구, 정종현, 피현구. 헤어드레서의 근골격계 통증수준과 관련 요인. 한국산업보건학회지, 27: 130-137, 2017.

정은희. 한국사회 우울과 소득의 종단적 상호관계: 사회 원인가설과 선택가설 검증을 중심으로. 정신보건과 사회사업, $46:$ 150-178, 2018.

조현열, 김영삼. 20-30대 헤어드레서의 환경요인과 직무스트레스로 인한 이직요인 분석. 아시안뷰티화장품학술지, 18 : 9-16, 2020.

허정애, 이정민. 미용사의 직무스트레스와 우울증 및 여가활동의 관련성. 한국미용학회지, 16: 1139-1150, 2010. 


\section{中文摘要}

\section{美发师的职业压力与抑郁之间的关系}

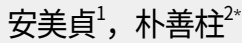

1安东大学护理学科, 庆尚北道安东市, 韩国

²龙仁大学美容经营学科, 京畿道龙仁市, 韩国

目的: 本研究旨在调查美发师的工作压力, 确定其与抑郁症的关系, 并确定影响抑郁症的因素。方法: 使用 SPSS/WIN 22.0，根据一般特征分析工作压力和抑郁水平。使用皮尔逊校正效应分析了工作压力与抑郁之 间的相关性。为了确定影响抑郁的因素, 使用了逐步多线应力分析。结果: 美发师的工作压力总平均得分为 $41.55 \pm 8.78$, 而抑郁症的平均得分为 $16.79 \pm 9.05$ 。似乎影响抑郁的变量包括补偿不足 $(t=7.30, p<0.001)$ ， 婚姻状况（ $t=-4.53, p<0.001) ， 工$ 作要求 $(t=2.53, p<0.012)$ ，年龄（ $t=2.77, p<0.006 ）$ 和工作场所文化 $(t=246, p<0.015)$ 。结论：根据这项研究的结果，建议制定一项针对工作压力和抑郁的干预计划，以改善美 发师的心理健康。

关键词: 美发师，工作压力，抑郁，薪酬不足，工作要求 
